\title{
Eficiências biológica e econômica de bovinos em terminação alimentados com dieta suplementar em pastagem de capim-marandu
}

\author{
Valéria Pacheco Batista Euclides ${ }^{(1)}$, Alexandre Scaff Raffi(2), Fernando Paim Costa( ${ }^{(1)}$, Kepler Euclides Filho ${ }^{(3)}$, \\ Geraldo Ramos Figueiredo(1) e Jean Amorim Ribeiro Costa ${ }^{(1)}$ \\ (1)Embrapa Gado de Corte, Rodovia BR 262, Km 04, Caixa Postal 154, CEP 79002-970 Campo Grande, MS. E-mail: val@cnpgc.embrapa.br, \\ paim@cnpgc.embrapa.br, geraldo@cnpgc.embrapa.br, manocrba@yahoo.com.br (2)Universidade para o Desenvolvimento do Estado e da \\ Região do Pantanal, Rua Ceará, no 33, Caixa Postal 2153, CEP 79003-010 Campo Grande, MS. E-mail: aleraffi@terra.com.br ${ }^{(3)}$ Embrapa \\ Sede, Parque Estação Biológica - PqEB, s/no, CEP 70770-901 Brasília, DF. E-mail: kepler.filho@embrapa.br
}

\begin{abstract}
Resumo - O objetivo deste trabalho foi avaliar as eficiências biológica e econômica de novilhos em terminação, em pastagem, que receberam suplementação durante o período seco. Trinta novilhos $1 / 2$ Braford $1 / 4$ Angus $1 / 4$ Nelore, separados em dois lotes com pesos corporais médios (PC) de 365 e $410 \mathrm{~kg}$, foram distribuídos em seis piquetes de capim-marandu, em delineamento experimental inteiramente casualizado, com três tratamentos e dez repetições. Os tratamentos foram constituídos pelos suplementos: sal-amireia; 0,6 e $1 \%$ do PC de concentrado. A cada 28 dias, os animais foram pesados, e a cobertura de gordura foi avaliada. Mensalmente, todos os piquetes foram amostrados para determinação da massa de forragem dos componentes morfológicos e do valor nutritivo. Os animais com suplementação de 1\% do PC de concentrado ganharam mais peso do que aqueles com $0,6 \%$ do $\mathrm{PC}$, e estes últimos mais do que aqueles que receberam sal-amireia. Consequentemente, houve relação inversa entre a dose de suplementação e o tempo necessário para os animais atingirem o ponto de acabamento. Independentemente do tratamento, os animais mais leves apresentaram margens líquidas superiores. Para os dois lotes, a maior margem líquida esteve associada à suplementação apenas com sal-amireia.
\end{abstract}

Termos para indexação: Brachiaria brizantha, amireia, Braford-Angus-Nelore, massa de forragem, período seco, valor nutritivo.

\section{Biological and economic efficiencies of steers in finishing period fed with supplementary diet in a palisade grass pasture}

\begin{abstract}
The objective of this work was to evaluate the biological and economic efficiencies of steers, in finishing period in a palisade grass pasture, with supplementation during the dry season. Thirty steers $1 / 2$ Braford $1 / 4$ Angus $1 / 4$ Nelore separated in two groups with initial live weights (LW) of $365 \mathrm{~kg}$ and $410 \mathrm{~kg}$ were assigned to six paddocks of palisade grass. The experimental design was completely randomized, with three treatments and ten replicates. The treatments consisted of the following supplements: mineral salt plus starea; 0,6 and $1 \%$ LW of concentrate. Animals were weighted each 28 days, and their fat thickness was determined. Forage was sampled monthly to determine its mass, morphological components and nutritive value. Animals supplemented with $1 \%$ of the LW gained more weight than those supplemented with $0,6 \%$ of the LW, and these last gained more weight than those supplemented with mineral salt plus starea. Consequently, there was an inverse relationship between supplementation and time for reaching the predefined end-point. Independently of treatment, the lighter steers showed higher net margins. For the two groups of animals, the largest net margin was associated with the mineral salt plus starea supplementation only.
\end{abstract}

Index terms: Brachiaria brizantha, starea, Braford-Angus-Nelore, forage mass, dry period, nutritive value.

\section{Introdução}

A estacionalidade de produção de forragem, característica comum das pastagens, talvez seja uma das maiores limitações à manutenção da uniformidade da produção ao longo do ano. Essa sazonalidade é caracterizada por marcante redução na produção de forragem e, consequentemente, na produção animal durante o período seco do ano. Algumas alternativas como a adubação e o manejo corretos das pastagens têm proporcionado sensíveis melhorias nos índices de produtividade. Todavia, tais estratégias não são suficientes para solucionar o problema de alimentação do gado, principalmente durante o período seco (Euclides et al., 2000, 2008). Isso se torna mais evidente em sistemas de produção que objetivam produzir carne de alta qualidade. 
Há consenso de que a maciez é a característica organoléptica, direta ou indiretamente, mais valorizada pelo consumidor (Feijó, 2001). Assim, a idade de abate exerce papel importante, uma vez que animais mais jovens tendem a produzir carne mais macia (Euclides Filho, 1998). A suplementação alimentar surge, neste contexto, como alternativa tecnológica efetiva e importante para acelerar o ganho de peso animal e para potencializar a utilização dos recursos forrageiros disponíveis. Apesar da estratégia de suplementação ser dependente da meta de desempenho animal que se deseja alcançar, sua escolha deverá também ser fundamentada em análise econômica. Assim, a rentabilidade da estratégia de suplementação alimentar constitui-se no norteador da escolha do suplemento a ser utilizado.

Numa tentativa de se estimar o efeito da suplementação alimentar sobre o ganho de peso animal e sobre a conversão alimentar, Euclides \& Medeiros (2005) construíram um banco de dados, fundamentado em trabalhos publicados no Brasil que utilizaram a suplementação alimentar em pastagens durante o período seco. Como resultado das análises realizadas com o uso de tais informações, os autores ressaltaram que as menores quantidades de suplemento proteico atenuaram a limitação dos baixos conteúdos de $\mathrm{N}$ das forragens no período seco e aumentaram a ingestão de matéria seca, o que resultou em maior consumo da forragem suplementada em relação à não suplementada e, consequentemente, em boa resposta à suplementação. À medida que se aumentou a oferta de concentrado, houve aumento do efeito substitutivo, o que resultou em ganhos de peso crescentes, porém em taxas decrescentes. Esses pontos levaram os autores a sugerir que suplementações mais modestas contribuiriam para a melhoria econômica dos sistemas produtivos, não apenas por terem custos menores, mas também pelo aumento da eficiência no uso dos insumos, especialmente pela maximização da utilização da forragem do pasto.

Além disso, em situações em que é atrativa a produção do novilho precoce, cuja terminação deve ocorrer entre 18 e 24 meses de idade, o uso de maiores quantidades de suplemento, como forma de aumentar o ganho de peso e promover o grau de acabamento adequado, torna-se fundamental e pode ser determinante no retorno econômico do empreendimento.
O objetivo deste trabalho foi avaliar as eficiências biológica e econômica de novilhos em terminação em pastagem, que receberam três níveis de suplementação, durante o período seco.

\section{Material e Métodos}

O experimento foi conduzido na Embrapa Gado de Corte, Campo Grande $\left(20^{\circ} 27^{\prime} \mathrm{S}, 5^{\circ} 37^{\prime} \mathrm{W}\right.$ e altitude, $530 \mathrm{~m}$ ), MS, de março de 2005 a janeiro de 2006. O padrão climático da região, segundo Köppen, é o da faixa de transição entre Cfa e Aw tropical úmido. A precipitação anual média é de $1.560 \mathrm{~mm}$, e o período de seca compreende os meses de maio a setembro $(30 \%$ da precipitação anual).

O solo da área experimental é classificado como Latossolo Vermelho distrófico (Claessen, 1997). Os pastos de Brachiaria brizantha (Syn. Urochloa) cv. Marandu foram recuperados em 1998 e são utilizados desde essa época. Os detalhes de adubação e de manejo podem ser encontrados em Euclides et al. (2007b).

A área experimental foi de 7,5 ha, dividida em seis piquetes - três de 1,5 ha e três de 1 ha. Esses pastos foram utilizados durante o período das águas sob lotação contínua, com taxa de lotação média de 1,5 UA ha-1, até o fim de fevereiro. Durante a primeira semana de março, eles foram usados intensivamente, tendo abaixado os resíduos para $10 \mathrm{~cm}$ de altura, e foram, então, diferidos. Nessa ocasião, foram aplicados, em cobertura, $110 \mathrm{~kg} \mathrm{ha}^{-1}$ de ureia.

Foram utilizados 30 novilhos $1 / 2$ Braford 1/4 Angus $1 / 4$ Nelore, castrados, com idade média de 19 meses e peso corporal entre 340 e $420 \mathrm{~kg}$. Esses animais foram recriados em pastos de capim-tanzânia, submetidos a diferentes níveis de adubação, por isso a grande variação no peso corporal, resultante do manejo adotado durante o período das águas. Optou-se por separá-los em dois lotes, um com os animais mais leves, com peso corporal médio de $365 \mathrm{~kg}$ (Lote 1), e o outro com os mais pesados, de peso corporal médio de $410 \mathrm{~kg}$ (Lote 2).

Os animais foram distribuídos ao acaso nos seis piquetes: no piquete de 1 ha, foram alocados quatro animais do Lote 2; e no piquete de 1,5 ha, foram alocados seis animais do Lote 1. O delineamento experimental foi inteiramente casualizado, com três tratamentos e dez repetições. Os tratamentos foram constituídos pelos suplementos: sal-amireia; 0,6 e $1 \%$ do peso corporal (PC) de um concentrado com 32,2\% 
de grãos de milho moído, $32,5 \%$ de farelo de soja, $29,8 \%$ de grãos de soja moído, $3,5 \%$ de mistura mineral e $2 \%$ de calcário calcítico, metade fornecido às $9 \mathrm{~h}$ e a outra metade às $15 \mathrm{~h}$. Os lotes testemunha receberam, à vontade, uma fórmula comercial de sal mineral com amireia, com $23 \%$ de proteína bruta.

Os animais foram suplementados a partir de 14 de julho até atingirem o ponto de acabamento, isto é, no mínimo $440 \mathrm{~kg}$ de PC e $4 \mathrm{~mm}$ de cobertura de gordura. As pesagens foram feitas após jejum de 16 horas, a cada 28 dias; a cobertura de gordura foi avaliada com o auxílio de um aparelho de ultrassom.

Os 12 animais que não atingiram o ponto de acabamento durante o período seco (20/9/2005) foram redistribuídos nos piquetes da seguinte forma: os três animais suplementados com $0,6 \%$ do PC foram transferidos para um piquete de 1 ha e continuaram recebendo o suplemento até o abate; os nove animais suplementados com sal-amireia foram distribuídos ao acaso, em três piquetes de 1,5 ha, e passaram a receber apenas mistura mineral até atingirem o ponto de abate.

Mensalmente, todos os piquetes foram amostrados. Para se estimar a massa de forragem foram cortadas, ao nível do solo, 25 e 40 amostras de $1 \mathrm{~m}^{2}$, ao acaso, para os piquetes de 1 e 1,5 ha, respectivamente. Essas foram divididas em duas subamostras: uma foi seca a $65^{\circ} \mathrm{C}$ e pesada, e a outra foi separada em lâmina foliar, colmo (bainha e colmo) e material morto. A proporção de cada componente morfológico foi expressa como percentagem da massa total na base da matéria seca.

Para cada piquete, foram feitas amostras compostas constituídas de cinco amostras de cada um dos componentes morfológicos (lâmina foliar, pseudocolmo e material morto). Essas amostras compostas foram moídas a $1 \mathrm{~mm}$ e analisadas para estimar os teores de proteína bruta $(\mathrm{PB})$, a digestibilidade in vitro da matéria orgânica (DIVMO), a fibra em detergente neutro (FDN) e a lignina em detergente ácido (LDA), tendo-se usado a espectroscopia de reflectância do infravermelho próximo (NIRS; Modelo NR5000: NIRS Systems, Inc., USA), de acordo com os procedimentos de Marten et al. (1985). Os dados de reflectância das amostras, na faixa de comprimentos de onda de 1.100 a $2.500 \mu \mathrm{m}$, foram armazenados em um espectrômetro acoplado a um microcomputador.

As ofertas de forragem e de lâminas foliares foram calculadas utilizando a massa de matéria seca total e a massa de matéria seca de lâminas foliares presentes, na ocasião da amostragem, divididas pelo total de peso corporal.

As variáveis associadas às características dos pastos foram analisadas por meio de modelo matemático que continha os efeitos fixos de tratamento, lote de animais e das suas interações. $\mathrm{O}$ efeito do mês do ano foi analisado como variável contínua. Com base em análises prévias, selecionou-se o polinomial de maior ordem para cada variável dependente.

O ganho de peso médio diário e o número de dias para atingir o ponto de abate foram analisados por meio de um modelo que continha os efeitos fixos de lote de animais, de suplementação e de meses do ano e suas interações. Foram analisadas, ainda, as correlações entre o ganho de peso médio diário e as características estruturais e o valor nutritivo da forrageira.

Todas as análises foram feitas pelo método dos quadrados mínimos, com o procedimento "general linear model" do SAS (SAS Institute, 1996). A comparação de médias foi realizada pelo teste de Tukey, a 5\% de probabilidade. No caso de interações significativas, a comparação de médias foi realizada por meio da probabilidade da diferença e pelo teste $\mathrm{t}$ de Student, a 5\% probabilidade.

$\mathrm{Na}$ análise econômica, dois sistemas diferenciados pelo peso inicial dos animais foram considerados: no sistema 1 (S1), o peso inicial foi de $365 \mathrm{~kg}$, enquanto no sistema 2 (S2) foi de $410 \mathrm{~kg}$. Custos e receitas de cada tratamento foram calculados para cada data de abate específica; posteriormente, os números obtidos para as diversas datas foram somados para obtenção dos resultados dos tratamentos. Como a quantidade de animais nos lotes dos sistemas $\mathrm{S} 1$ e S2 era diferente, os dados econômicos foram expressos por cabeça bovina.

Os custos incluíram os seguintes itens: suplemento alimentar (definido pelos tratamentos); sal mineral, dado apenas aos animais que não atingiram condições de abate até fim de outubro; aluguel da pastagem, dependente do tempo transcorrido até o abate; animais (preços diferentes para S1 e S2, em razão dos pesos iniciais distintos); e outros custos, como depreciação e conservação de instalações e benfeitorias, limpeza da pastagem, produtos veterinários, combustível e lubrificantes, salários e encargos dos empregados, serviços gerais e contador, impostos e taxas, energia elétrica e telefone, e pró-labore do produtor. Estes 
"outros custos" foram obtidos a partir de valores expressos por unidade-animal (UA) e por mês, baseados em dados apresentados por Costa et al. (2008), referentes a setembro de 2007 e ajustados para outubro de 2009, com base no IGP-DI da Fundação Getúlio Vargas.

Os benefícios dos tratamentos compreendem a receita da venda dos animais e os juros decorrentes da antecipação do abate (em relação à média de duração do tratamento testemunha), ponderados pelo número de animais abatidos em cada data. Nesse cálculo, considerou-se uma taxa real de $6 \%$ ao ano, remuneração equivalente a uma aplicação conservadora como a caderneta de poupança. Subtraídos os custos dos benefícios obteve-se a margem líquida, com base na qual os sistemas puderam ser cotejados segundo seu desempenho econômico.

Considerando-se que o produtor está sujeito aos riscos decorrentes da variação de preços de insumos e produtos, optou-se por dar tratamento estocástico aos preços dos principais ingredientes da ração (milho em grão, farelo de soja e grão de soja), do boi magro e do boi gordo. Para os ingredientes da ração, consideraram-se os preços correntes no mês de março de cada ano do período 2001/2009; em relação ao boi magro, tomou-se o mês de maio para o mesmo período; em relação ao boi gordo, utilizaram-se os preços correntes nos meses de agosto, setembro, outubro e novembro (meses de maior concentração dos abates) para o período 2001/2009. Esses preços correntes, que tiveram como principal fonte os boletins pecuários semanais editados pelo Instituto FNP (2009), foram transformados em preços reais de outubro de 2009, tendo-se usado como "inflator" o Índice Geral de Preços - Disponibilidade Interna (IGP-DI) da Fundação Getúlio Vargas. Pressupondo-se que os preços têm distribuição aproximadamente normal, foi calculado as médias e os desvios-padrão, com base nas quais empregou-se a técnica de simulação Monte Carlo (Ladaga \& Berger, 2006), para gerar valores aleatórios em uma sequência de 150 iterações. Assim, as variáveis dependentes desses preços passaram à condição de variáveis aleatórias, para as quais se calcularam médias, máximos, mínimos e probabilidades de ocorrência de valores negativos (para a margem líquida).

\section{Resultados e Discussão}

Não houve efeito de lote de animais $(\mathrm{p}>0,05)$ e da interação $(p>0,05)$ entre os efeitos de lote de animais e nível de suplementação. No entanto, os animais com suplementação de $1 \%$ do PC de concentrado ganharam mais peso $(\mathrm{p}<0,01)$ do que aqueles com $0,6 \%$ do $\mathrm{PC}$, e estes mais do que aqueles que receberam sal-amireia (Tabela 1). Tais resultados concordam com as observações feitas por Euclides \& Medeiros (2005) e Silva et al. (2009), com base em banco de dados fundamentados em trabalhos publicados no Brasil, e que utilizaram a suplementação alimentar durante o período seco. Neste caso, observou-se que quando se aumenta a quantidade de suplemento, há incremento do ganho de peso do animal. No entanto, quando se comparou o desempenho dos animais suplementados com sal-amireia àqueles de animais suplementados com sal proteinado, observou-se que o ganho médio diário (GMD) de $485 \mathrm{~g}$ por animal foi maior do que os GMD de 125, 160 e $150 \mathrm{~g}$ por animal, observados por Knorr et al. (2005) e Moreira et al. (2003, 2004), que suplementaram novilhos em pasto nativo com sal-amireia e em pasto de capim-estrela com sal proteinado, respectivamente.

Durante o período seco, as massas de forragem $(\mathrm{p}>0,05)$, as variáveis associadas aos componentes estruturais do pasto $(\mathrm{p}>0,05)$ e as variáveis associadas ao valor nutritivo da forragem $(p>0,05)$ foram semelhantes para os pastos utilizados nos diferentes tratamentos. Também, não houve interações $(p>0,05)$ com os efeitos de suplementação e de meses, durante o período de utilização para todas as variáveis associadas à caracterização dos pastos. Assegurou-se, desta forma, que as diferenças em ganho de peso médio diário (GMD) fossem consequência da suplementação.

Foi observada interação $(p<0,05)$ entre os efeitos de níveis de suplementação e do período de avaliação, durante a estação seca. Independentemente do nível de suplementação usado, o GMD foi semelhante no

Tabela 1. Ganho médio diário \pm erro padrão da média (grama por dia) dos animais 1/2 Braford 1/4 Angus 1/4 Nelore, de acordo com as doses de suplementação e os meses durante o período $\operatorname{seco}^{(1)}$.

\begin{tabular}{lcccc}
\hline Período & \multicolumn{2}{c}{ Doses de concentrado (\% do peso corporal) } & \multirow{2}{*}{ Médias } \\
\cline { 2 - 4 } & $0^{(2)}$ & 0,6 & 1,0 & \\
\hline Junho/julho & $840 \pm 81 \mathrm{Aa}$ & $830 \pm 81 \mathrm{Aa}$ & $1.180 \pm 81 \mathrm{Aa}$ & $950 \pm 47$ \\
Julho/agosto & $495 \pm 81 \mathrm{Bb}$ & $895 \pm 81 \mathrm{Aa}$ & $1.085 \pm 81 \mathrm{Aa}$ & $825 \pm 47$ \\
Agosto/setembro & $20 \pm 81 \mathrm{Cb}$ & $700 \pm 88 \mathrm{Aa}$ & $1.068 \pm 139 \mathrm{Aa}$ & $595 \pm 63$ \\
\hline Média & $485 \pm 49 \mathrm{c}$ & $775 \pm 65 \mathrm{~b}$ & $1.130 \pm 71 \mathrm{a}$ & \\
\hline${ }^{(1)}$ Médias seguidas de letras iguais, maiúsculas nas colunas e minúsculas nas \\
linhas, não diferem entre si pelo teste de Tukey, a 5\% de probabilidade. \\
${ }^{(2)}$ Sal-amireia (23\% de PB), consumo médio de 120 g por novilho por dia.
\end{tabular}

Pesq. agropec. bras., Brasília, v.44, n.11, p.1536-1544, nov. 2009 
período junho/julho. Nos outros períodos, todavia, os animais que receberam apenas sal-amireia ganharam menos peso do que aqueles que receberam concentrado nas quantidades de 0,6 e $1 \%$ do PC (Tabela 1). Houve decréscimo no ganho de peso, ao longo do período seco, apenas nos animais que receberam sal-amireia, o que mostra que esse tipo de suplementação não foi suficiente para compensar os decréscimos lineares $(p<0,01)$ em massa de forragem de matéria seca total $\left(\mathrm{MST}=3180-12,04 \mathrm{x}, \mathrm{R}^{2}=0,66\right)$, matéria seca verde $\left(\mathrm{MSV}=1910-18,7 \mathrm{x}, \mathrm{R}^{2}=0,83\right)$, matéria seca de lâmina foliar $\left(\mathrm{MSLF}=1060-12,22 \mathrm{x}, \mathrm{R}^{2}=0,87\right)$, e em valor nutritivo (Figura 1) do pasto. Decréscimos no GMD, ao longo do período seco, também foram observados por Ítavo et al. (2008), em novilhos em pastos de capim-marandu, suplementados com $145 \mathrm{~g}$ de sal-amireia por animal por dia; por Agulhon et al. (2005), em vacas em pastos de capim-marandu, que receberam suplemento concentrado a 0,5 e $1 \%$ do PC; e por Santos et al. (2009), em novilhos em pastos diferidos de Urochloa decumbens, alimentados com suplemento concentrado a $0,4 \%$ do PC.
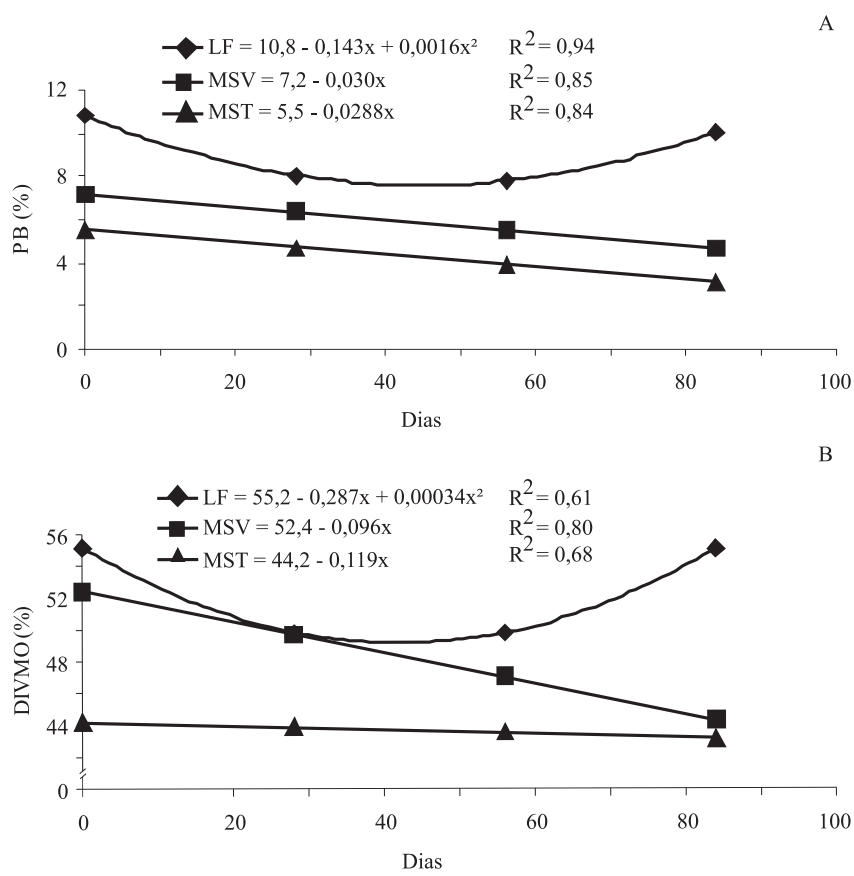

Figura 1. Relações entre os teores de proteína bruta (PB) (A) e digestibilidade in vitro da matéria orgânica (DIVMO) (B), da lâmina foliar (LF) da fração verde (MSV) e da planta inteira (MST), com os dias de utilização dos pastos de capim-marandu, durante o período seco de 14 de junho a 14 de setembro de 2005 .
Todavia, independentemente da quantidade, o concentrado usado foi efetivo para compensar os decréscimos na quantidade e na qualidade da forragem, neste período (Tabela 1). Resultados semelhantes foram encontrados por Gesualdi Júnior et al. (2000), Gomes Júnior et al. (2002) e Brito et al. (2008), em novilhos suplementados com concentrado durante o período seco.

Verifica-se que o ganho de peso dos animais suplementados com sal-amireia foi função tanto do valor nutritivo quanto das massas e das ofertas de forragem (Tabela 1). No primeiro período (junho/julho), quando a oferta de forragem foi mais elevada (7,5 kg de MST; 4,7 kg de MSV; e 2,5 kg de MSLF por $100 \mathrm{~kg}$ de PC por dia), e os teores de PB e DIVMO da MSLF (Figura 1) foram adequados, não houve diferença entre os ganhos de peso dos animais que receberam apenas sal-amireia e os ganhos daqueles suplementados com concentrado nas quantidades 0,6 e $1 \%$ do PC (Tabela 1 ).

No segundo período, julho/agosto, houve decréscimos tanto na oferta de forragem $(7 \mathrm{~kg}$ de MST; 3,6 kg de MSV; e 1,3 kg de MSLF por $100 \mathrm{~kg}$ de PC por dia) quanto no conteúdo de PB dos pastos (Figura 1). Apesar do menor ganho de peso observado nos animais suplementados com sal-amireia, quando comparados com aqueles obtidos pelos animais que receberam concentrado 0,6 e 1\% PC, essa suplementação foi efetiva em prover o animal com proteína a ser utilizada pelos microrganismos do rúmen, o que melhorou a digestão da fibra e, consequentemente, a ingestão de forragem e a produção animal. Nesse caso, o GMD foi de $495 \mathrm{~g}$, superior ao normalmente observado em animais não suplementados em pastos de gramíneas tropicais durante o período seco (Almeida et al., 2003; Brâncio et al., 2003; Euclides et al., 2007a; Euclides et al., 2008).

De agosto a setembro, apesar de a oferta de forragem total (6,2 kg de MST por $100 \mathrm{~kg}$ de PC por dia) não ter sido expressivamente mais baixa do que nos períodos anteriores, as ofertas de MSV e de MSF foram muito baixas (1,3 kg de MSV; e 0,2 kg de MSLF por $100 \mathrm{~kg}$ de PC por dia), o que, provavelmente, limitou a ingestão de forragem pelos animais. Assim, a correção de parte da proteína foi suficiente apenas para a manutenção de peso (Tabela 1), uma vez que, além da deficiência proteica, havia deficiência energética resultante do baixo teor de DIVMO (Tabela 2) no pasto, aliado ao baixo consumo de forragem. Isso confirma a sugestão 
feita por Euclides \& Medeiros (2005) de que o uso de sal proteinado só é indicado quando a disponibilidade de forragem não for limitante.

Foi observada, também, interação $(p>0,05)$ entre os efeitos de lote (peso inicial) e meses, durante a estação seca. Exceto para o período de julho/agosto, os GMD dos animais do Lote 1 foram superiores aos do Lote 2. Como a idade foi semelhante entre os dois lotes, o peso alterou a eficiência do crescimento dos animais, uma vez que a eficiência de crescimento de bovinos de corte é função de duas características: a taxa de ganho e a composição química dos tecidos depositados. Segundo Lanna (1997), a deposição de peso na forma de músculo é cerca de quatro vezes mais eficiente que a deposição de tecido adiposo. Como o ponto de acabamento dos animais era de, no mínimo, $4 \mathrm{~mm}$ de cobertura de gordura, os animais do lote mais pesado passaram, proporcionalmente, mais tempo depositando tecido adiposo.

Houve diferença no tempo necessário para os animais atingirem o ponto de acabamento (Figura 2). Todos os animais suplementados com 1\% PC foram abatidos durante o período seco. Dos dez animais suplementados com $0,6 \%$ do PC, apenas sete foram abatidos nesse período. Os três animais (Lote 1) restantes continuaram a ser suplementados até atingirem o ponto de acabamento (Tabela 3). No entanto, dos animais que receberam sal-amireia, apenas um (Lote 2) atingiu o ponto de abate, durante o período seco (Tabela 3), os outros foram distribuídos, ao acaso, nos pastos (1,5 ha) e passaram a receber apenas mistura mineral até atingirem o ponto de abate (Figura 2). Independentemente dos níveis de suplementação, os animais do Lote 1 precisaram, em média, de mais um mês para atingiram o ponto de acabamento (Figura 2).

Os quatro pastos utilizados no período das águas foram semelhantes $(p>0,05)$ quanto à massa de

Tabela 2. Ganho médio diário \pm erro padrão da média (g por dia) dos animais $1 / 2$ Braford $1 / 4$ Angus $1 / 4$ Nelore, de acordo com o peso inicial e os meses, durante o período seco ${ }^{(1)}$.

\begin{tabular}{lcc}
\hline Período & Lote $1(365 \mathrm{~kg})$ & Lote $2(410 \mathrm{~kg})$ \\
\hline Junho/julho & $1.085 \pm 60 \mathrm{Aa}$ & $815 \pm 73 \mathrm{Ab}$ \\
Julho/agosto & $760 \pm 60 \mathrm{Ba}$ & $890 \pm 73 \mathrm{Aa}$ \\
Agosto/setembro & $625 \pm 60 \mathrm{Ca}$ & $280 \pm 130 \mathrm{Bb}$ \\
\hline Média & $820 \pm 34$ & $720 \pm 56$ \\
\hline
\end{tabular}

${ }^{(1)}$ Médias seguidas de letras iguais, maiúsculas nas colunas e minúsculas nas linhas, não diferem entre si pelo teste de Tukey, a 5\% de probabilidade. forragem, estrutura do dossel e valor nutritivo da forragem. As médias e os erros padrão da média para a oferta de forragem foram iguais a $17,2(1,3) \mathrm{kg}$ de MST por $100 \mathrm{~kg}$ de PC por dia; e a $8,4(0,8) \mathrm{kg}$ de MSLF por $100 \mathrm{~kg}$ de PC por dia. Para o valor nutritivo, as médias e desvios-padrão da média foram 9,6 $(0,5)$, $59,3(1,5), 69,4(0,8)$ e 2,7 $(0,2)$, para os teores de PB, DIVMO, FDN e LDA, respectivamente.

Os ganhos de peso médio diários foram semelhantes ( $p>0,18$ ) entre os animais que receberam $0,6 \%$ do PC de suplemento e aqueles que receberam sal mineral, em média 780 e 630 g por novilho, respectivamente. Esses resultados indicam a menor eficiência da suplementação alimentar, durante o período das águas. Resultados semelhantes foram encontrados por Zervoudakis

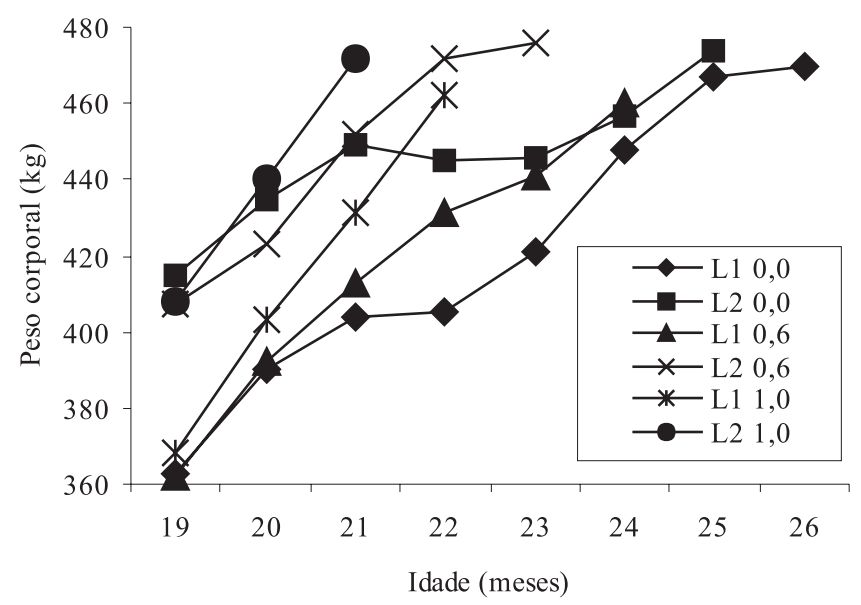

Figura 2. Relações entre o peso corporal e a idade necessária para os animais atingirem o ponto de acabamento, de acordo com a média de peso inicial (L1, $365 \mathrm{~kg}$; L2, $410 \mathrm{~kg})$, com as doses de suplemento (0, 0,6 e 1\% do PC), de 14 de junho de 2005 a 15 de janeiro 2006.

Tabela 3. Cronologia de abates, de acordo com o peso inicial (Lote 1, $365 \mathrm{~kg}$; Lote 2, $410 \mathrm{~kg}$ ) dos animais e as doses de suplementação utilizadas ( $\mathrm{T}$, testemunha; $\mathrm{T}$ 0,6, 0,6\% do peso corporal; T 1, $1 \%$ do peso corporal).

\begin{tabular}{|c|c|c|c|c|c|c|}
\hline \multirow[t]{2}{*}{ Data de abate } & \multicolumn{2}{|c|}{$\mathrm{T}^{(1)}$} & \multicolumn{2}{|c|}{ Т 0,6} & \multicolumn{2}{|c|}{ T 1,0} \\
\hline & Lote 1 & Lote 2 & Lote 1 & Lote 2 & Lote 1 & Lote 2 \\
\hline 9 de agosto & - & - & - & 1 & - & 4 \\
\hline 6 de setembro & - & 1 & 1 & 2 & 6 & - \\
\hline 20 de setembro & - & - & 2 & 1 & - & - \\
\hline 20 de outubro & - & 2 & 1 & - & - & - \\
\hline 24 de novembro & - & 1 & 2 & - & - & - \\
\hline 21 de dezembro & 5 & - & - & - & - & - \\
\hline 15 de janeiro & 1 & - & - & - & - & - \\
\hline
\end{tabular}

${ }^{(1)}$ Sal-amireia (23\% de PB), consumo médio de $120 \mathrm{~g}$ por novilho por dia. 
et al. (2001) e Paulino et al. (2006), que forneceram suplementação alimentar para animais mantidos em capim-marandu, durante o período das águas.

A maior margem líquida das seis alternativas é aquela da suplementação sal-amireia (T) do sistema 1 (S1, animais mais leves), da ordem de $\mathrm{R} \$ 248,36$ por cabeça, seguida da mesma suplementação do sistema 2 (S2, animais mais pesados), no valor de R\$ 170,71 por cabeça (Tabela 4). A alternativa S1-T não teve a maior receita, mas apresentou o menor custo, o que resultou em maior margem líquida. A alternativa suplementação com $1 \%$ do PC (T 1,0), para o S2, é um caso interessante, pois detém a maior receita e, apesar disso, a menor margem líquida, consequência de seu maior custo. É possível afirmar então que, para as condições deste trabalho, as alternativas de suplementação com apenas sal-amireia são as mais viáveis do ponto de vista econômico, e que os resultados pioram com o uso crescente de suplemento. Também é notória a vantagem dos bovinos mais leves e mais baratos, embora a suplementação com $0,6 \%$ do PC $(\mathrm{T} 0,6)$ tenha apresentado maior margem líquida em S2. Essas observações estão de acordo com as de Euclides \& Medeiros (2005), que afirmam que suplementações mais modestas contribuiriam para a melhoria econômica dos sistemas produtivos, não apenas por terem custos menores, mas também pelo aumento da eficiência no uso dos insumos, especialmente pela maximização da utilização da forrageira.
A Figura 3 expõe a média e a amplitude de variação das margens líquidas das seis alternativas analisadas, considerando-se a série de 150 iterações geradas pelo método Monte Carlo. Nota-se que a alternativa $\mathrm{S} 1-\mathrm{T}$ apresenta dominância estocástica sobre todas as demais, pois sua margem líquida tem a maior média, o maior máximo e o menor mínimo, além de ter a menor probabilidade de ocorrência de valor negativo, no caso $10 \%$. Em segundo lugar, vem $\mathrm{S} 2-\mathrm{T}$, que domina as demais alternativas, com exceção de $\mathrm{S} 1-\mathrm{T}$; a probabilidade de ocorrência de valor negativo para sua margem líquida é de $19 \%$.

Entre as alternativas que incluem o fornecimento de suplementos (T 0,6 e T 1 em S1 e S2, Figura 3), a maior média e o maior valor máximo foram registrados para $\mathrm{S} 2-\mathrm{T} 0,6$, embora essa alternativa não tenha o menor mínimo (observado para $\mathrm{S} 1-\mathrm{T}$ $0,6)$. Têm-se, ainda, as seguintes probabilidades estimadas para margens líquidas negativas de: 31 ; $38 ; 29$ e $43 \%$, respectivamente, para os tratamentos: S1-T 0,6; S1-T 1; S2-T 0,6; S2-T 1.

Essas constatações confirmam a natureza estratégica da suplementação alimentar, em animais mantidos em pastagem no período seco. Variações em seu desempenho ponderal e outros coeficientes técnicos, bem como na relação de preços, com ênfase no boi gordo e no suplemento, podem levar a resultados distintos, o que implica dizer que, no processo de tomada de decisão, cada caso precisa ser analisado de acordo com suas especificidades técnicas e econômicas.

Tabela 4. Valores médios ${ }^{(1)}(\mathrm{R} \$)$ - de outubro de 2009, por cabeça bovina - relativos a custos, receitas e margem líquida dos sistemas S1 (animais com peso inicial de $365 \mathrm{~kg}$ ) e S2 (animais com peso inicial de $410 \mathrm{~kg}$ ), nos tratamentos testemunha (T), suplementação de $0,6 \%$ do peso vivo (T 0,6) e suplementação de $1 \%$ do peso vivo (T 1).

\begin{tabular}{|c|c|c|c|c|c|c|}
\hline \multirow[t]{2}{*}{ Itens } & \multicolumn{3}{|c|}{$\mathrm{S} 1$} & \multicolumn{3}{|c|}{$\mathrm{S} 2$} \\
\hline & $\mathrm{T}$ & T 0,6 & $\mathrm{~T} 1$ & $\mathrm{~T}$ & T 0,6 & T 1 \\
\hline Custos (b) & $1.012,28$ & $1.133,61$ & $1.186,79$ & $1.072,20$ & $1.165,00$ & $1.251,48$ \\
\hline Suplemento $^{(2)}$ & 15,59 & 188,40 & 256,44 & 14,94 & 141,46 & 239,00 \\
\hline Sal mineral ${ }^{(3)}$ & 6,43 & 0,00 & 0,00 & 0,75 & 0,00 & 0,00 \\
\hline Aluguel da pastagem & 72,59 & 45,74 & 36,64 & 47,01 & 27,91 & 20,94 \\
\hline Animais & 869,67 & 869,67 & 869,67 & 976,89 & 976,90 & 976,89 \\
\hline Outros custos & 48,00 & 29,80 & 24,04 & 32,61 & 18,73 & 14,65 \\
\hline Receitas (a) & $1.260,64$ & $1.234,35$ & $1.257,33$ & $1.242,91$ & $1.285,73$ & $1.293,19$ \\
\hline Animais abatidos & $1.260,64$ & $1.225,65$ & $1.243,59$ & $1.242,91$ & $1.266,92$ & $1.270,52$ \\
\hline Juros - antecipação abate & 0,00 & 8,70 & 13,74 & 0,00 & 18,81 & 22,67 \\
\hline Margem líquida $(\mathrm{a}-\mathrm{b})$ & 248,36 & 100,74 & 70,54 & 170,71 & 120,73 & 41,71 \\
\hline
\end{tabular}

${ }^{(1)}$ Médias para as 150 iterações obtidas via método Monte Carlo. ${ }^{(2)}$ No tratamento testemunha, foram fornecidos apenas sal e amiréia. ${ }^{(3)}$ Apenas para os animais que não atingiram peso de abate até o final de outubro. 
S1

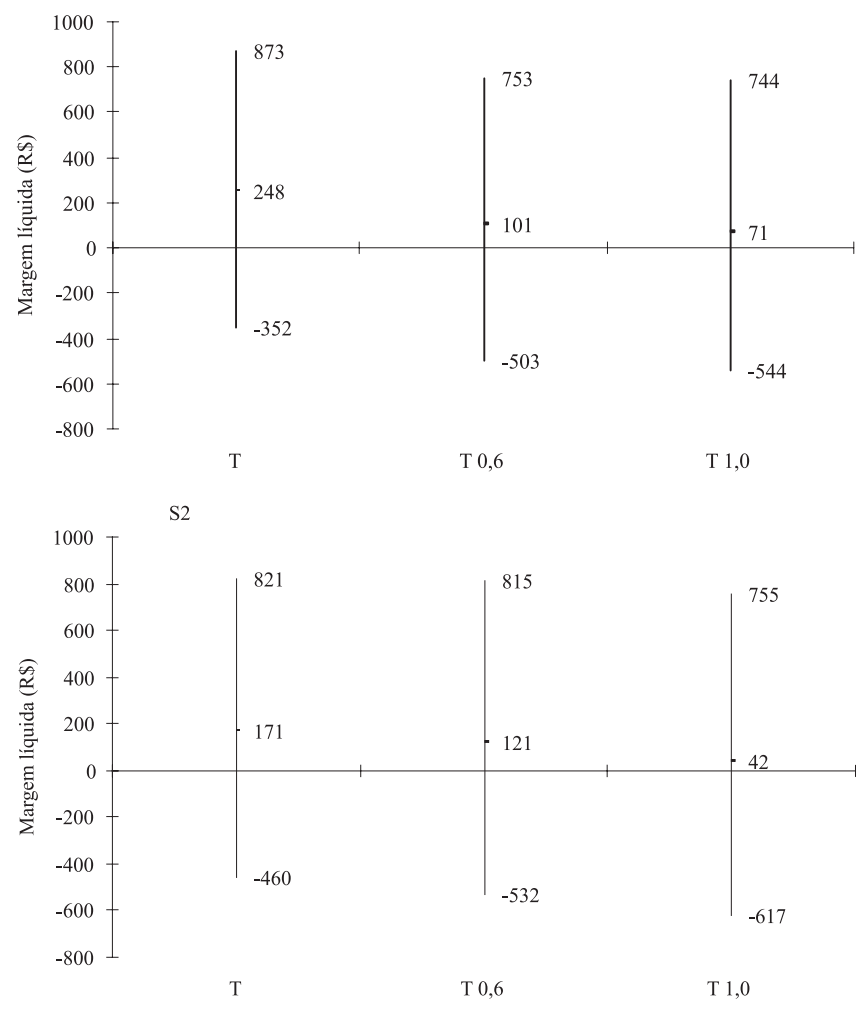

Figura 3. Médias, máximos e mínimos da margem líquida para os tratamentos testemunha $(\mathrm{T})$, suplementação de $0,6 \%$ do peso vivo (T 0,6$)$, e suplementação de $1 \%$ do peso vivo ( T 1,0), nos sistemas S1 (animais com peso inicial de $365 \mathrm{~kg}$ ) e no S2 (animais com peso inicial de $410 \mathrm{~kg}$ ).

\section{Conclusões}

1. É possível terminar animais $1 / 2$ Braford $1 / 4$ Angus $1 / 4$ Nelore, com 22 meses de idade, quando se utiliza suplementação concentrada na quantidade de $1 \%$ do peso corporal, durante o período seco.

2. Quando se utiliza suplementação concentrada mais moderada - de $0,6 \%$ do peso corporal - com o objetivo de terminar o animal com menos de 24 meses, o peso corporal do novilho $1 / 2$ Braford $1 / 4$ Angus $1 / 4$ Nelore, no início do período seco, deve ser superior a $410 \mathrm{~kg}$.

3. Ganhos de peso superiores, propiciados por doses maiores de suplementação, mostram-se antieconômicos, conforme relação de preços vigente.

4. O ganho de peso dos bovinos mais pesados não compensa seu maior custo de aquisição, como indicam as margens líquidas calculadas.

\section{Referências}

AGULHON, R.A.; JOBIM, C.C.; BRANCO, A.F.; CALIXTO JÚNIOR, M. Fontes energéticas e níveis de suplementação para vacas em pastagem de capim-marandu (Brachiaria brizantha Hochst ex. A. Rich. Stapf) no inverno. Revista Brasileira de Zootecnia, v.34, p.151-158, 2005.

ALMEIDA, R.G.de;EUCLIDES, V.P.B.;NASCIMENTOJUNIOR, D. do; MACEDO, M.C.M; FONSECA, D.M da; BRÂNCIO, P.A.; BARBOSA, R.A. Consumo, composição botânica e valor nutritivo da dieta de bovinos em pastos tropicais consorciados sob três taxas de lotação. Revista Brasileira de Zootecnia, v.32, p.29-35, 2003.

BRÂNCIO, P.A.; NASCIMENTO JUNIOR, D. do; EUCLIDES, V.P.B.; FONSECA, D.M. da; ALMEIDA, R.G. de; MACEDO, M.C.M.; MACEDO, M.C.M.; BARBOSA, R.A. Avaliação de três cultivares de Panicum maximum Jacq. sob pastejo: composição da dieta, consumo de matéria seca e ganho de peso animal. Revista Brasileira de Zootecnia, v.32, p.1037-1044, 2003.

BRITO, R.M. de; SAMPAIO, A.A.M.; FERNANDES, A.R.M.; RESENDE, K.T. de; HENRIQUE, W.; TULLIO, R.R. Desempenho de bezerros em pastagem de capim-marandu recebendo suplementação com concentrados balanceados para diferentes níveis de produção. Revista Brasileira de Zootecnia, v.37, p.1641-1649, 2008.

CLAESSEN, M.E.C. (Org.). Manual de métodos de análise de solo. 2.ed. rev. atual. Rio de Janeiro: Embrapa-CNPS, 1997. 212p.

COSTA, F.P.; CORRÊA, E.S.; MELO FILHO, G.A. de; CARDOSO, E.E. Custos de produção de gado de corte em Mato Grosso do Sul - setembro de 2007. Campo Grande: Embrapa Gado de Corte, 2008. 17p. (Embrapa Gado de Corte. Comunicado técnico, 111).

EUCLIDES FILHO, K. A situação do melhoramento genético com relação à maciez da carne bovina e sua importância para a pecuária de corte brasileira. In: WORKSHOP QUALIDADE DA CARNE E MELHORAMENTO GENÉTICO DE BOVINOS DE CORTE, 1., 1998, São Carlos. Estado da arte, necessidade de pesquisa e direcionamento de programas de melhoramento genético: anais. São Carlos: Embrapa-CPPSE, 1998. p.105-113.

EUCLIDES, V.P.B.; CARDOSO, E.G.; MACEDO, M.C.M; OLIVEIRA, M.P. Consumo voluntário de Brachiaria decumbens cv. Basilisk e Brachiaria brizantha cv. Marandu sob pastejo. Revista Brasileira de Zootecnia, v.29, p.2200-2208, 2000.

EUCLIDES, V.P.B.; COSTA, F.P.; MACEDO, M.C.M.; FLORES, R.; OLIVEIRA, M.P. de. Eficiências biológica e econômica de pasto de capim-tanzânia adubado com nitrogênio no final do verão. Pesquisa Agropecuária Brasileira, v.42, p.1345-1355, 2007a.

EUCLIDES, V.P.B.; FLORES, R.; MEDEIROS, R.N.; OLIVEIRA, M.P. de. Diferimento de pastos de braquiária cultivares Basilisk e Marandu, na Região do Cerrado. Pesquisa Agropecuária Brasileira, v.42, p.273-280, $2007 \mathrm{~b}$.

EUCLIDES, V.P.B.; MACEDO, M.C.M.; ZIMMER, A.H.; JANK, L.; OLIVEIRA, M.P. de. Avaliação dos capins mombaça e massai sob pastejo. Revista Brasileira de Zootecnia, v.37, p.18-26, 2008. 
EUCLIDES, V.P.B.; MEDEIROS, S.R. de. Suplementação alimentar de bovinos em pastagens. In: CARVALHO, L. de A.; ZOCCAL, R.; MARTINS, P. do C.; ARCURI, P.B.; MOREIRA, M.S. de P. (Ed.). Tecnologia e gestão na atividade leiteira. Juiz de Fora: Embrapa Gado de Leite, 2005. p.203-240.

FEIJÓ, G.L.D.; COSTA, F.P.; FEIJÓ, R.M.B. Carne de vitelão: estudo exploratório de um mercado potencial. Campo Grande: Embrapa Gado de Corte, 2001. 21p. (Embrapa Gado de Corte. Documentos, 105).

FNP. Anualpec 2009. São Paulo: FNP, 2009.

GESUALDI JÚNIOR, A.; PAULINO, M.F.; VALADARES FILHO, S. de C.; SILVA, J.F.C. da; VELOSO, C.M.; CECON, P.R. Níveis de concentrado na dieta de novilhos F1 Limousin x Nelore: consumo, conversão alimentar e ganho de peso. Revista Brasileira de Zootecnia, v.29, p.1458-1466, 2000.

GOMES JÚNIOR, P.; PAULINO, M.F.; DETMANN, E.; VALADARES FILHO, S. de C.; ZERVOUDAKIS, J.T.; LANA, R. de P. Desempenho de novilhos mestiços na fase de crescimento suplementados durante a época seca. Revista Brasileira de Zootecnia, v.31, p.139-147, 2002.

ÍTAVO, L.C.V.; TOLENTINO, T.C.P.; ÍTAVO, C.C.B.F.; GOMES, R.C.; DIAS, A.M.; SILVA, F.F. Consumo, desempenho e parâmetros econômicos de novilhos Nelore e F1 Brangus x Nelore terminados em pastagens, suplementados com mistura mineral e sal nitrogenado com ureia ou amireia. Arquivo Brasileiro de Medicina Veterinária e Zootecnia, v.60, p.419-427, 2008.

KNORR, M.; PATINO, H.O.; SILVEIRA, A.L.F. da; MÜHLBACH, P.R.F.; MALLMANN, G.M.; MEDEIROS, F.S. Desempenho de novilhos suplementados com sais proteinados em pastagem nativa. Pesquisa Agropecuária Brasileira, v.40, p.783-788, 2005.

LADAGA, S.P. de; BERGER, A. Toma de decisiones en el sector agropecuario. Herramientas de investigación operativa aplicadas al agro. Buenos Aires: Universidad de Buenos Aires, 2006. 308p.

LANNA, D.P.D. Fatores condicionantes e predisponentes da puberdade e da idade de abate. In: SIMPÓSIO SOBRE PECUÁRIA
DE CORTE, 4., 1996, Piracicaba. Produção do novilho precoce: anais. Piracicaba: FEALQ, 1997. p.41-78.

MARTEN, G.C.; SHENK, J.S.; BARTON II, F.E. Near infrared reflectance spectroscopy (NIRS): analysis of forage quality. Washington: USDA, 1985, 110p. (Agriculture Handbook, 643).

MOREIRA, F.B.; PRADO, I.N. do; CECATO, U.; WADA, F.Y.; NASCIMENTO, W.G. do; SOUZA, N.E. de. Suplementação com sal mineral proteinado para bovinos de corte, em crescimento e terminação, mantidos em pastagem de grama-estrela roxa (Cynodon plectostachyrus Pilger), no inverno. Revista Brasileira de Zootecnia, v.32, p.449-455, 2003.

MOREIRA, F.B.; PRADO, I.N. do; CECATO, U.; ZEOULA, L.M.; WADA, F.Y.; TORII, M.S. Níveis de suplementação com sal mineral proteinado para novilhos Nelore terminados em pastagem no período de baixa produção forrageira. Revista Brasileira de Zootecnia, v.33, p.1814-1821, 2004.

PAULINO, M.F.; MORAES, E.H.B.K. de; ZERVOUDAKIS, J.T.; ALEXANDRINO, E.; FIGUEIREDO, D.M. de. Terminação de novilhos mestiços leiteiros sob pastejo, no período das águas, recebendo suplementação com soja. Revista Brasileira de Zootecnia, v.35, p.154-158, 2006.

SANTOS, M.E.R; FONSECA, D.M. da; EUCLIDES, V.P.B; RIBEIRO JÚNIOR, J.I.; NASCIMENTO JÚNIOR, D. do; MOREIRA, L. de M. Produção de bovinos em pastagens de capim-braquiária diferidas. Revista Brasileira de Zootecnia, v.38, p.635-642, 2009.

SAS INSTITUTE.SAS/STAT software: changes and enhancements thorough release. Version 6.11. Cary: SAS Institute, 1996.

SILVA, F.F. da; SÁ, J.F. de; SCHIO, A.R.; ÍTAVO, L.C.V.; SILVA, R.R.; MATEUS, R.G. Suplementação a pasto: disponibilidade e qualidade x níveis de suplementação x desempenho. Revista Brasileira de Zootecnia, v.38, p.371-389, 2009.

ZERVOUDAKIS, J.T.; PAULINO, M.F.; DETMANN, E.; LANA, R. de P.; VALADARES FILHO, S. de C.; CECON, P.R.; QUEIROZ, D.S. de; MOREIRA, A.L. Desempenho e característica de carcaça de novilhos suplementados no período das águas. Revista Brasileira de Zootecnia, v.30, p.1381-1389, 2001.

Recebido em 5 de janeiro de 2009 e aprovado em 29 de outubro de 2009 